\title{
WHAT DETERMINES THE WAVELENGTH OF SELF-ORGANIZED SHORELINE SAND WAVES?
}

\begin{abstract}
Albert Falqués ${ }^{1}$, Niels van den Berg ${ }^{1}$, Francesca Ribas ${ }^{1}$ and Miquel Caballeria ${ }^{2}$
Shoreline undulations extending into the bathymetric contours with a length scale larger than that of the rhythmic surf zone bars are referred to as shoreline sand waves. Many observed undulations along sandy coasts display a wavelength in the order 1-7 km. Several models that are based on the hypothesis that sand waves emerge from a morphodynamic instability in case of very oblique wave incidence predict this range of wavelengths. Here we investigate the physical reasons for the wavelength selection and the main parametric trends of the wavelength in case of sand waves arising from such instability. It is shown that the existence of a minimum wavelength depends on an interplay between three factors affecting littoral drift: (A) the angle of wave fronts relative to local shoreline, which tends to cause maximum transport at the downdrift flank of the sand wave, (B) the refractive energy spreading which tends to cause maximum transport at the updrift flank and (C) wave focusing (de-focusing) by the capes (bays), which tends to cause maximum transport at the crest or slightly downdrift of it. Processes A and C cause decay of the sand waves while process B causes their growth. For low incidence angles, B is very weak so that a rectilinear shoreline is stable. For large angles and long sand waves, B is dominant and causes the growth of sand waves. For large angles and short sand waves $\mathrm{C}$ is dominant and the sand waves decay. Thus, wavelength selection depends on process $\mathrm{C}$, which essentially depends on shoreline curvature. The growth rate of very long sand waves is weak because the alongshore gradients in sediment transport decrease with the wavelength. This is why there is an optimum or dominant wavelength. It is found that sand wave wavelength scales with $\lambda_{0} / \beta$ where $\lambda_{0}$ is the water wave wavelength in deep water and $\beta$ is the mean bed slope from shore to the wave base.
\end{abstract}

Keywords: shoreline sand waves, shoreline instability, wave driven longshore transport, high angle waves

\section{INTRODUCTION}

Shoreline sand waves are undulations of the shoreline that extend into the bathymetry up to a certain depth. Some of them are linked to surfzone rhythmic bars (megacusps) but we will here focus on those that are not necessarily linked to surfzone bars and that in general occur at larger length and time scales, i.e., km's and yr's. These shoreline sand waves are episodically or persistently found along many sandy coasts (Bruun 1954, Verhagen, 1989, Inman et al. 1992, Thevenot and Kraus 1995, Gravens 1999, Guillén et al. 1999, Stive et al. 2002, Ruessink and Jeuken 2002, Davidson-Arnott and van Heyningen 2003, Medellín et al. 2008, Alves 2009, Vila-Concejo et al. 2009, Falqués et al. 2011a, Kaergaard et al. 2011, Ryabchuk et al. 2011). They can be triggered by different physical mechanisms, including forcing by offshore bathymetric anomalies or input of large quantities of sand at inlets and rivers, but they can also emerge from irregularities of an otherwise rectilinear coast in absence of any forcing at their length scale. This can occur if the wave climate is dominated by high-angle waves, i.e., waves with a high incidence angle relative to the shore normal, because the rectilinear coast becomes unstable (Ashton et al. 2001, Ashton et al. 2006a, Falqués et al. 2011b) and we will hereinafter refer to them as free or self-organized sand waves. The critical water wave angle for instability is about $45^{\circ}$ at the depth of closure, i.e., at the most offshore reach of the bathymetric perturbations (van den Berg et al. 2012a).

The first modelling study on 'High angle wave instability', hereinafter referred to as HAWI, did not predict any preferred wavelength, both the wavelength and amplitude of shoreline perturbations increased in time (Ashton et al. 2001). Furthermore, there was no lower limit on the growing wavelengths. Falqués and Calvete (2005) showed that the absence of wavelength selection occurred because the model of Ashton et al. (2001) did not take the curvature of bathymetric contours into account. If this is accounted for into the wave transformation from deep water up to breaking, there is a cut-off wavelength $L_{c}$ below which sand waves do not grow and an initially dominant wavelength $L_{M}$ emerges. This wavelength selection was first obtained with linear stability models (Falqués and Calvete 2005, Uguccioni et al. 2006) but has recently been confirmed with a nonlinear morphodynamic model (van den Berg et al. 2012a). It depends on a number of factors such as the cross-shore beach profile, wave height, period and angle. Falqués and Calvete (2005) obtained a range $L_{M} \sim 3-15 \mathrm{~km}$ by examining mild beach slopes in the range 0.005-0.02 whereas van den Berg et al. (2012a) obtained wavelengths

\footnotetext{
${ }^{1}$ Departament de Física Aplicada, Universitat Politècnica de Catalunya, Campus Nord UPC B5, Barcelona, Catalonia, 08034, Spain

${ }^{2}$ Escola Politècnica Superior, Universitat de Vic, C/ de la Laura 13, Vic, Catalonia, 08500, Spain
} 
about 2-5 km for a slope of 0.03. For steeper beaches, wavelengths in the range 0.6-1.5 km may appear (Caballeria et al. 2011) and even shorter wavelengths of 100-200 m can exceptionally occur in case of a very steep beach and very particular wave conditions (Medellín et al. 2009). Thus, the wavelength selection for self-organized shoreline sand waves is a robust output of the models provided that the curvature of the bathymetric contours is not ignored. Furthermore, this wavelength selection in the range of several km's is reasonably supported by some existing studies and a preliminary inspection of satellite images https://maps.google.es/maps/ms?ie=UTF8\&hl=fr\&oe=UTF8\&msa=0\&msid=203478154407587240864 .0004 c03cc7b1f821cafa8 and Fig. 1).

The physical explanation for the existence of a dominant wavelength at the initial development of HAWI are still unclear. Falqués and Calvete (2005) made some computations for the limit of very short sand waves and showed that in that case there was a strong increase of water wave refraction at the lee of the sand wave, bringing the maximum in wave energy from updrift to downdrift of the crest. As a result the short sand waves decayed (Falqués et al. 2011b) and there was a lower limit for the growing wavelengths. This gives just a clue, since the computations were done with the linearized equations, for very particular conditions and with an unrealistically short wavelength $(100 \mathrm{~m})$. Moreover, an equivalent analysis for the limit of long sand waves was not provided.

The first aim of the present contribution is to investigate the physical mechanism that causes a wavelength selection for free shoreline sand waves. The second aim is to find out on which parameters this wavelength depend. Both computations and observations suggest that the wavelength decreases for increasing beach slope (Medellín et al. 2009, Caballeria et al. 2011). Thus, there is a need for a systematic exploration of this parametric trend and of the sensitivity to other parameters like wave height, period and angle. A linear stability model (Falqués and Calvete 2005) is used and in section 2, the model equations are presented. The behavior of the gradients in alongshore sediment transport as a function of the wavelength is investigated in section 3 in order to find out the physical processes that are responsible for the wavelength selection. In section 4 an exploration is done to find the main parametric trends. Discussion and some conclusions are presented in section 5.

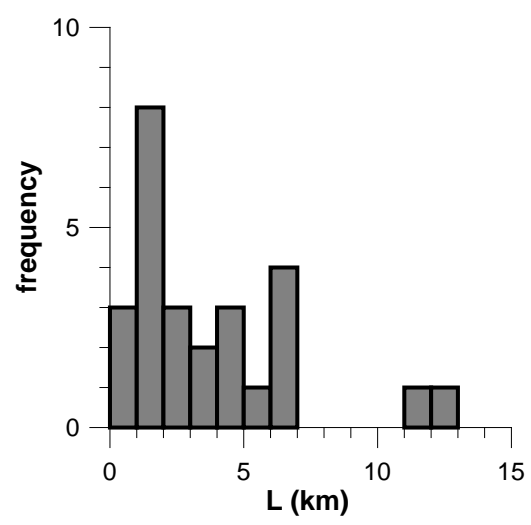

Figure 1. Frequency versus wavelength for observed shoreline sand waves. Source: https://maps.google.es/maps/ms?ie=UTF8\&hl=fr\&oe=UTF8\&msa=0\&msid=203478154407587240864.0004c03cc7b1f821cafa 8.

\section{MODEL EQUATIONS}

\section{Governing equations}

Since we are interested in coastal morphodynamics at large length and time scales in case of oblique wave incidence we will use the so-called one-line modelling where the changes in coastline position are just caused by the gradients in alongshore transport rate $\mathrm{Q}$ according to

$$
D_{a} \frac{\partial x_{s}}{\partial t}=-\frac{\partial Q}{\partial y}
$$

We here consider a cartesian reference frame where y runs along the mean shoreline, $\mathrm{x}$ runs seaward in the cross-shore direction and $\mathrm{z}$ is directed upwards. The nearshore bathymetry is $\mathrm{z}=\mathrm{z}_{\mathrm{b}}(\mathrm{x}, \mathrm{y}, \mathrm{t})$ and the position of the shoreline is $\mathrm{x}=\mathrm{x}_{\mathrm{s}}(\mathrm{y}, \mathrm{t})$ where $\mathrm{t}$ is time. The effective water depth of the morphodynamic 
active region is $D_{a}$ and the porosity factor is included in $Q$ for simplicity. The computation of the integrated transport rate $\mathrm{Q}\left(\mathrm{m}^{3} / \mathrm{s}\right)$ is typically based on $\mathrm{H}_{\mathrm{b}}$ and $\alpha_{\mathrm{b}}$, i.e., the (rms) wave height and the angle of the wave fronts with respect to the local shoreline orientation at breaking. We will here consider the widely used CERC formula (Komar 1998),

$$
Q=\mu H_{b}^{5 / 2} \sin \left(2 \alpha_{b}\right)
$$

where $\mu$ is an empirical constant of order $0.15-0.2 \mathrm{~m}^{1 / 2} \mathrm{~s}^{-1}$ (Falqués and Calvete 2005) and the value $\mu=0.15$ is taken here. Other empirical expressions for $Q$ are expected to give qualitatively similar results (Ashton et al. 2006b). The relative wave angle is $\alpha=\theta-\phi$ where $\theta$ is the angle of wave fronts and $\phi=$ $\tan ^{-1}\left(\partial \mathrm{x}_{\mathrm{s}} / \partial \mathrm{y}\right)$ is the angle of the shoreline with respect to the $\mathrm{y}$ axis. The rms wave height is considered through all the paper.

For a rectilinear coastline with parallel depth contours, $H_{b}$ and $\alpha_{b}$ are alongshore uniform so that there are no gradients in $\mathrm{Q}$ and the shoreline position is constant in time. If we introduce an undulation of the coastline, gradients in $\phi$ arise and, thereby also in Q, so that according to Eq. 1 the shoreline is no longer stationary. This process is described by the traditional one-line shoreline equation, which describes the diffusive behavior of shoreline perturbations (Pelnard-Considère 1956). However, the changes in shoreline position are linked to changes in the nearshore bathymetry that in turn cause changes in $H_{b}$ and $\theta_{b}$, which are ignored by the traditional one-line approach. Remarkably, these changes are the key point of HAWI (Falqués et al. 2011b). Thus, $\mathrm{H}_{\mathrm{b}}$ and $\theta_{\mathrm{b}}$ cannot be considered constant but must be computed from the deep water quantities, $\mathrm{H}_{0}$ and $\theta_{0}$, as a function of the changing bathymetry. Since the bathymetry is not a dynamic unknown of the governing equation, Eq. 1, the link between shoreline and bathymetry is done in a parametric way

$$
z_{b}(x, y, t)=-D(x, y, t)=-D_{0}(x)+D_{0}\left(x_{s}(y, t)\right) f\left(x-x_{s}(y, t)\right)
$$

The unperturbed water depth is $\mathrm{D}_{0}(\mathrm{x})$ with $\mathrm{D}_{0}(0)=0$ so that the unperturbed shoreline is located at $x=0$. The function $f(x)$ is a decreasing shape function such that $f(0)=1$ and $f(x)=0$ for $x \geq x_{c}$. It defines the shape of the bathymetric perturbation and $x_{c}$ determines its offshore extent.

Since we are interested in the basic parametric trends regarding the wavelength of sand waves we will consider a simple description of water waves but still keeping the basic processes of refraction and shoaling. To this aim, the optical approximation for monochromatic waves of wavelength $\lambda_{0}$, height $\mathrm{H}_{0}$ and angle $\theta_{0}$ in deep water is used. Thus, their transformation up to breaking will be described by the dispersion relation,

$$
\omega^{2}=g k \tanh (k D)
$$

where $\omega=\left(2 \pi \mathrm{g} / \lambda_{0}\right)^{1 / 2}$ is the radian frequency, $\mathrm{k}$ is their wavenumber and $\mathrm{g}$ is gravity acceleration, together with the crest conservation equation,

$$
\frac{\partial}{\partial x}(k \sin \theta)=\frac{\partial}{\partial y}(-k \cos \theta)
$$

and the energy conservation equation (up to breaking),

$$
\frac{\partial}{\partial x}\left(-c_{g} H^{2} \cos \theta\right)+\frac{\partial}{\partial y}\left(c_{g} H^{2} \sin \theta\right)=0
$$

where $c_{g}$ is the group celerity.

The shoreline equation, Eq. 1, with sediment transport given by Eq. 2, linked to the bathymetry through Eq. 3, together with the water wave equations, 4, 5, 6 constitute a complete set of equations to determine the unknowns $\mathrm{x}_{\mathrm{s}}(\mathrm{y}, \mathrm{t}), \mathrm{D}(\mathrm{x}, \mathrm{y}, \mathrm{t}), \mathrm{k}(\mathrm{x}, \mathrm{y}, \mathrm{t}), \theta(\mathrm{x}, \mathrm{y}, \mathrm{t})$ and $\mathrm{H}(\mathrm{x}, \mathrm{y}, \mathrm{t})$. Thinking of alongshore periodic perturbations on an unbounded coast, the integration domain for the water wave equations is defined as all $(\mathrm{x}, \mathrm{y})$ such that $\mathrm{x} \geq \mathrm{x}_{\mathrm{b}}(\mathrm{y}, \mathrm{t})$, where the breaking line $\mathrm{x}_{\mathrm{b}}$ is defined by $\mathrm{H}\left(\mathrm{x}_{\mathrm{b}}, \mathrm{y}, \mathrm{t}\right)=\gamma_{\mathrm{b}} \mathrm{D}\left(\mathrm{x}_{\mathrm{b}}, \mathrm{y}, \mathrm{t}\right)$ and only offshore boundary conditions are needed,

$$
k(\infty, y, t)=2 \pi / \lambda_{0}, \quad \theta(\infty, y, t)=\theta_{0}, \quad H(\infty, y, t)=H_{0}
$$

\section{Method: Linear Stability Analysis}

Linear stability analysis is a powerful tool to explore the initial tendency of the morphodynamic system to develop sand waves due to HAWI. Here we will use the so-called 1D-morfo linear stability 
model that was described in Falqués and Calvete (2005). Since the details are given in that paper, we will here just outline the main aspects. A sinusoidal shoreline undulation

$$
x_{s}(y, t)=a e^{\sigma t+i K y}+\text { c.c. }
$$

of small amplitude $\mathrm{A}=2$ a and wavelength $\mathrm{L}=2 \pi / \mathrm{K}$ is assumed. The corresponding bathymetry follows from the linearization of Eq. 3 for $\mathrm{a} \rightarrow 0$ :

$$
D(x, y, t)=D_{0}(x)-\beta_{s} f(x) x_{s}(y, t)
$$

where $\beta_{\mathrm{s}}$ is the beach slope at the shoreline. The shape function $\mathrm{f}(\mathrm{x})$ will be specified later on. Once the perturbed bathymetry is defined, the water wave equations $4,5,6$ are linearized for $\mathrm{a} \rightarrow 0$ and the perturbed wave height and angle at breaking are obtained (the computations are not straightforward, see Falqués and Calvete (2005)). This allows to compute the linearized sediment transport rate (Eq. 2) and inserting Eq. 8 into Eq. 1 and linearizing leads to the computation of the complex growth rate, $\sigma=\sigma_{\mathrm{r}}$ $+\mathrm{i} \sigma_{\mathrm{i}}$ for each wavelength, L. Those perturbations with $\sigma_{\mathrm{r}}>0$ will grow in time and the wavelength $\mathrm{L}_{\mathrm{M}}$ where $\sigma_{\mathrm{r}}(\mathrm{L})$ is maximum corresponds to the fastest growing sand wave, which is in principle the one expected to be dominant in nature. The imaginary part gives the alongshore propagation celerity of the sand waves, according to $\mathrm{V}=-\sigma_{\mathrm{i}} / \mathrm{K}$. It must be bore in mind that this analysis gives just the tendency of the system to develop free sand waves of a certain wavelength $\mathrm{L}$. It can be expected that the actual behavior of the sand waves with a given amplitude is not far from the predictions of the linear stability model while the amplitude is relatively small. However, this expectation needs to be checked with nonlinear modeling (van den Berg et al. 2012a).

\section{WAVELENGTH SELECTION MECHANISM}

The wavelength selection for small amplitude free shoreline sand waves can be illustrated with the typical instability curve (growthrate as a function of wavelength) shown in Fig. 2. We have chosen the bathymetry

$$
D_{0}(x)=B\left((x+d)^{2 / 3}-d^{2 / 3}\right)
$$

which is essentially a Dean profile where $d$ introduces a small shift to represent a finite slope at the shoreline (Falqués and Calvete 2005). The constants d, B are chosen by prescribing the beach slope at the shoreline, $\beta_{s}$, and the water depth, $\mathrm{D}_{1}$, at a certain offshore distance, $\mathrm{x}_{1}$,

$$
\frac{2}{3} B d^{-1 / 3}=\beta_{s}, \quad B\left(\left(x_{1}+d\right)^{2 / 3}-d^{2 / 3}\right)=D_{1}
$$

The default values used in this study are $\beta_{\mathrm{s}}=0.03, \mathrm{x}_{1}=700 \mathrm{~m}$ and $\mathrm{D}_{1}=10 \mathrm{~m}$. Regarding the perturbed bathymetry, an exponential-type shape function that goes to zero at $\mathrm{x}=\mathrm{x}_{\mathrm{C}}$

$$
f(x)=\frac{e^{-x / b}-e^{x_{c} / b}}{1-e^{x_{c} / b}}
$$

is considered. The b parameter is the e-folding length of the exponential decay. However, this actually only applies for $\mathrm{b}<<\mathrm{x}_{\mathrm{c}}$. If $\mathrm{b}$ is comparable or larger than $\mathrm{x}_{\mathrm{c}}, \mathrm{f}(\mathrm{x})$ becomes approximately a linear decay between 0 and $x_{c}$. We choose this situation for the present study with $b=500 \mathrm{~m}$ and $x_{c}=700 \mathrm{~m}$. This avoids that $b$ interferes with the essential lengthscales of the problem. The depth of closure, that is, the depth at the offshore extent of the perturbation, is $\mathrm{D}_{c}=\mathrm{D}_{0}\left(\mathrm{x}_{\mathrm{c}}\right)=10 \mathrm{~m}$. The wave parameters are $\mathrm{H}_{0}=1$ $\mathrm{m}, \theta_{0}=60^{\circ}, T=6 \mathrm{~s}$ at $\mathrm{D}=10 \mathrm{~m}$. The breaking index is $\gamma_{\mathrm{b}}=0.6$. It is seen that there is a minimum or cutoff wavelength, $\mathrm{L}_{\mathrm{c}}=1.75 \mathrm{~km}$, below which sand waves decay. For $\mathrm{L}>\mathrm{L}_{\mathrm{c}}$ sand waves grow and reach a maximum growthrate for $\mathrm{L}=\mathrm{L}_{\mathrm{M}}=2.53 \mathrm{~km}$. For $\mathrm{L}>\mathrm{L}_{\mathrm{M}}$ they always keep on growing but with a decreasing growth rate as $L$ increases. It seems that $\sigma_{\mathrm{r}}$ tends asymptotically to 0 for $\mathrm{L} \rightarrow \infty$. It is important however to mention that for very exceptional conditions the instability curves may have a more complex shape with more than one maximum (van den Berg et al. 2012b).

\section{Role of the gradients in $\mathbf{Q}$}

To understand the existence of both $\mathrm{L}_{\mathrm{c}}$ and $\mathrm{L}_{\mathrm{M}}$ we will consider a small amplitude sinusoidal sand wave along an otherwise rectilinear coastline with wavelength L. Both the perturbation in shoreline orientation and the perturbation in the wave field induced by the perturbed bathymetry will create alongshore gradients in sediment transport rate Q. If the amplitude is very small, the alongshore distribution of $\mathrm{Q}$ will consist of an average value plus a small sinusoidal perturbation with the same wavelength, L. Let us consider a crest of the sand wave $(\mathrm{C}: \mathrm{y}=0)$, the updrift and downdrift embayments 
(B1: $y=-L / 2, B 2: y=L / 2$ ) and the corresponding inflection points (I1: $y=-L / 4$, I2: $y=L / 4$ ) (see Fig. 3). If the maximum in $\mathrm{Q}$ is located at $\mathrm{I} 1$ (and the minimum at $\mathrm{I} 2$ ), the minimum in $\partial \mathrm{Q} / \partial \mathrm{y}$ is located at $\mathrm{C}$, whereas maxima in $\partial \mathrm{Q} / \partial \mathrm{y}$ will occur at $\mathrm{B} 1, \mathrm{~B} 2$.

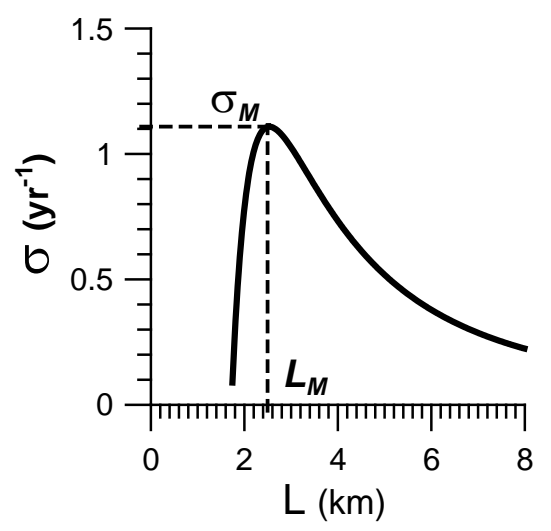

Figure 2. Typical instability curve: real growthrate as a function of wavelength.

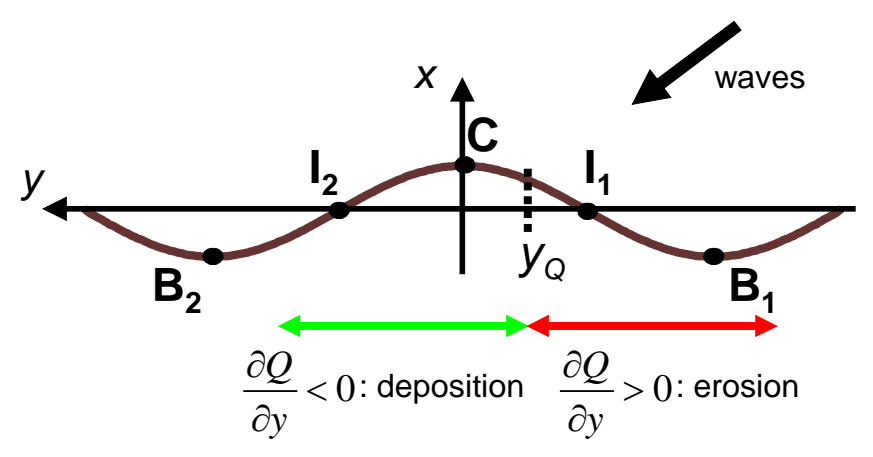

Figure 3. Sketch of the neighborhood of a sand wave crest (C) with the adjacent inflexion points and embayments, showing the maximum in sediment transport rate at $y=y_{Q}$. The situation where the gradients in $Q$ cause growth and downdrift translation of the sand wave is represented.

According to the sediment conservation equation, Eq. 1, there will be maximum accretion at $\mathrm{C}$ and maximum erosion at B1, B2, so that the sand wave will grow without translating. In case the maximum in Q occurs between I1 and C, the minimum in $\partial \mathrm{Q} / \partial \mathrm{y}$ will shift downdrift, in between $\mathrm{C}$ and $\mathrm{I} 2$, so that the sand wave will growth and will translate downdrift. Thus, the position of the maximum in $\mathrm{Q}$ with respect to B1,I1,C,I2,B2 determines the growth/decay and translation of the sand wave. More details can be seen in Falqués and Calvete (2005, List and Ashton (2007 and van den Berg (2012a).

\section{Location of the maximum in $\mathbf{Q}$}

We now examine the position of the maximum in $\mathrm{Q}, \mathrm{y}_{\mathrm{Q}}$, as a function of $\mathrm{L}$ for the model setup of Fig. 2, which is shown in Fig. 4. For a very small $\mathrm{L}$, the maximum is located downdrift of the crest so that there is decay of the sand wave along with downdrift migration. As L increases, $\mathrm{y}_{\mathrm{Q}}$ shifts updrift and for $\mathrm{L}=1.75 \mathrm{~km}$ it crosses the crest and moves updrift of it. This means that the sand wave will grow and it is fully consistent with Fig. 2. For larger $L$ the maximum continues to shift updrift at a lower rate and for $\mathrm{L} \geq 10 \mathrm{~km}$ seems to stay somewhat downdrift of the updrift inflexion point, $\mathrm{y}_{\mathrm{Q}} \approx-0.19 \mathrm{~L}$. This means that the sand wave will always grow for $\mathrm{L}>1.75 \mathrm{~km}$, again in accordance with figure 2 .

Even though the behavior of $\mathrm{y}_{\mathrm{Q}}$ explains the existence of a cutoff wavelength, we would like to know the physical processes behind this behavior. According to Eq. 2, $\mathrm{Q}$ is proportional to both $\mathrm{H}_{\mathrm{b}}{ }^{5 / 2}$ and $\sin \left(2 \alpha_{b}\right)$. Therefore, $y_{Q}$ is related to the position of the maxima in $H_{b}\left(y=y_{H}\right)$ and $\alpha_{b}\left(y=y_{\alpha}\right)$ within $-\mathrm{L} / 2 \leq \mathrm{y} \leq \mathrm{L} / 2$, which are plotted in figure 4 as a function of $\mathrm{L}$. It is seen that the maximum in $\mathrm{Q}$ is always located in between those two maxima, $\mathrm{y}_{\mathrm{H}}<\mathrm{y}_{\mathrm{Q}}<\mathrm{y}_{\alpha}$. Since $\alpha_{\mathrm{b}}=\theta_{\mathrm{b}}-\phi$ and $\theta_{\mathrm{b}}$ is relatively small, 
$\mathrm{y}_{\alpha}$ is located near the position of the minimum in $\phi$, which is exactly at the inflexion point, $\mathrm{y}=0.25 \mathrm{~L}$. Thus $\mathrm{y}_{\alpha}$ stays somewhat updrift of I2 with little changes that depend on $\theta_{\mathrm{b}}$. In contrast, the position of the maximum in $\mathrm{H}_{b}$ moves updrift from $y_{H}=0.07 \mathrm{~L}$ for $\mathrm{L}=0.5 \mathrm{~km}$ to $\mathrm{y}_{\mathrm{H}}=-0.21 \mathrm{~L}$ for $\mathrm{L}=10 \mathrm{~km}$. This is very notorious and means that for very short sand waves the maximum in wave height is somewhat downdrift of the crest while for long sand waves it is near the I1 inflexion point. It is striking that for $\mathrm{L}=0.5 \mathrm{~km} \mathrm{y}_{\mathrm{Q}}$ is closer to $\mathrm{y}_{\alpha}$ than to $\mathrm{y}_{\mathrm{H}}$. In contrast, for increasing $\mathrm{L}, \mathrm{y}_{\mathrm{Q}}$ follows the updrift shift of $\mathrm{y}_{\mathrm{H}}$
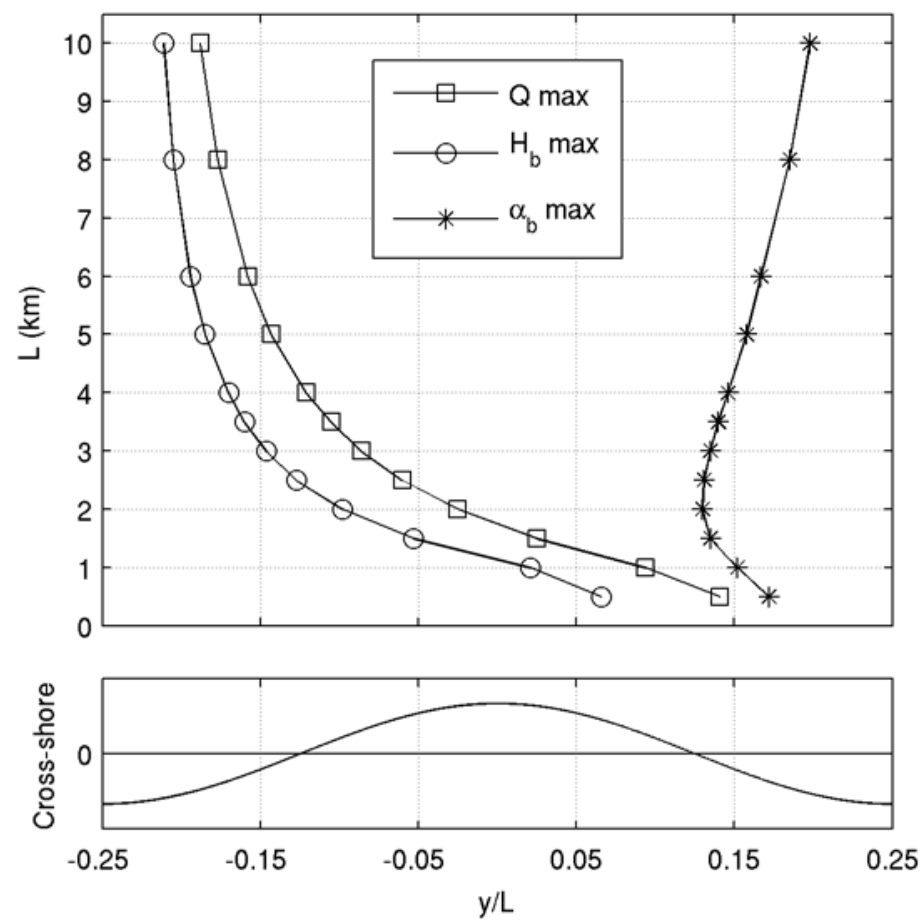

Figure 4. Alongshore location of the maxima of $Q(y), y_{Q}, H_{b}(y), y_{H}$ and of $\alpha_{b}(y), y_{\alpha}$, as a function of the wavelength, $\mathrm{L}$.

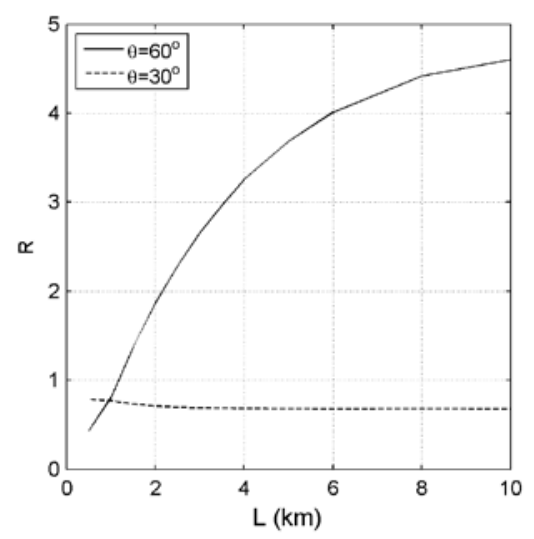

Figure 5. Relative importance of the gradients of $H_{b}$ and the gradients of $\alpha_{b}$ on the gradients of $Q$, as a function of wavelength, $L$. The ratio $R=D_{H} \Delta H_{b} / D_{\alpha} \Delta \alpha_{b}$ is plotted, where $D_{H}, D_{\alpha}$ are the coefficients in Eq. 13 and $\Delta \mathrm{H}_{b}, \Delta \alpha_{b}$ are the corresponding maximum alongshore variations. Both unstable $\left(\theta_{0}=60^{\circ}\right.$, continuous line) and stable $\left(\theta_{0}=30^{\circ}\right.$, dashed line) conditions are represented. $A$ small amplitude $A=33 \mathrm{~m}$ has been assumed to compute $\Delta \mathrm{H}_{\mathrm{b}}$ and $\Delta \alpha_{\mathrm{b}}$.

and becomes much closer to $\mathrm{y}_{\mathrm{H}}$. This can be understood by looking at the relative importance of the alongshore gradients in $\mathrm{H}_{\mathrm{b}}$ and $\alpha_{\mathrm{b}}$. Small variations $\mathrm{H}_{\mathrm{b}}$ ' and $\alpha_{\mathrm{b}}$ ' will cause a small variation in $\mathrm{Q}$, 


$$
Q^{\prime}=\mu H_{b}^{5 / 2}\left(\frac{5}{2} \frac{H_{b}{ }^{\prime}}{H_{b}} \sin 2 \alpha_{b}+2 \alpha_{b}{ }^{\prime} \cos 2 \alpha_{b}\right)=D_{H} H_{b}{ }^{\prime}+D_{\alpha} \alpha_{b}{ }^{\prime}
$$

Then, the relative importance of $\mathrm{H}_{\mathrm{b}}$ and $\alpha_{\mathrm{b}}$ can be estimated with the ratio $\mathrm{D}_{\mathrm{H}} \mathrm{H}_{\mathrm{b}}{ }^{\prime} / \mathrm{D}_{\alpha} \alpha_{\mathrm{b}}$ ' by taking $\mathrm{H}_{\mathrm{b}}{ }^{\prime}$ $=\Delta \mathrm{H}_{\mathrm{b}}$ and $\alpha_{\mathrm{b}}{ }^{\prime}=\Delta \alpha_{\mathrm{b}}$, where $\Delta \mathrm{H}_{\mathrm{b}}$ and $\Delta \alpha_{\mathrm{b}}$ are the maximum alongshore variations of $\mathrm{H}_{\mathrm{b}}$ and $\alpha_{\mathrm{b}}$, respectively. This ratio is represented as a function of $\mathrm{L}$ in Fig. 5. It is found that for small $\mathrm{L}$, both terms are comparable while for moderate to large $\mathrm{L}, \mathrm{D}_{\mathrm{H}} \Delta \mathrm{H}_{\mathrm{b}}>>\mathrm{D}_{\alpha} \Delta \alpha_{\mathrm{b}}$. Thus, for moderate to large $\mathrm{L}$ the gradients in $\mathrm{Q}$ are controlled by the gradients in $\mathrm{H}_{\mathrm{b}}$ while for small $\mathrm{L}$ both the gradients in both $\mathrm{H}_{\mathrm{b}}$ and $\alpha_{\mathrm{b}}$ play a similar role.

\section{The alongshore gradients in wave energy}

The updrift shift of $\mathrm{y}_{\mathrm{H}}$ for increasing wavelength is a result of a similar shift in the alongshore maximum of the wave height $\mathrm{H}(\mathrm{x}, \mathrm{y})$ in the nearshore. For very short sand waves the maximum in wave energy is located somewhat downdrift of C (consistently with Falqués and Calvete (2005)). In contrast, for larger wavelengths that maximum shifts updrift of the crest, in between I1 and C. Fig. 5 presents an example of this behavior for the cases $\mathrm{L}=1 \mathrm{~km}$ and $\mathrm{L}=2 \mathrm{~km}$.

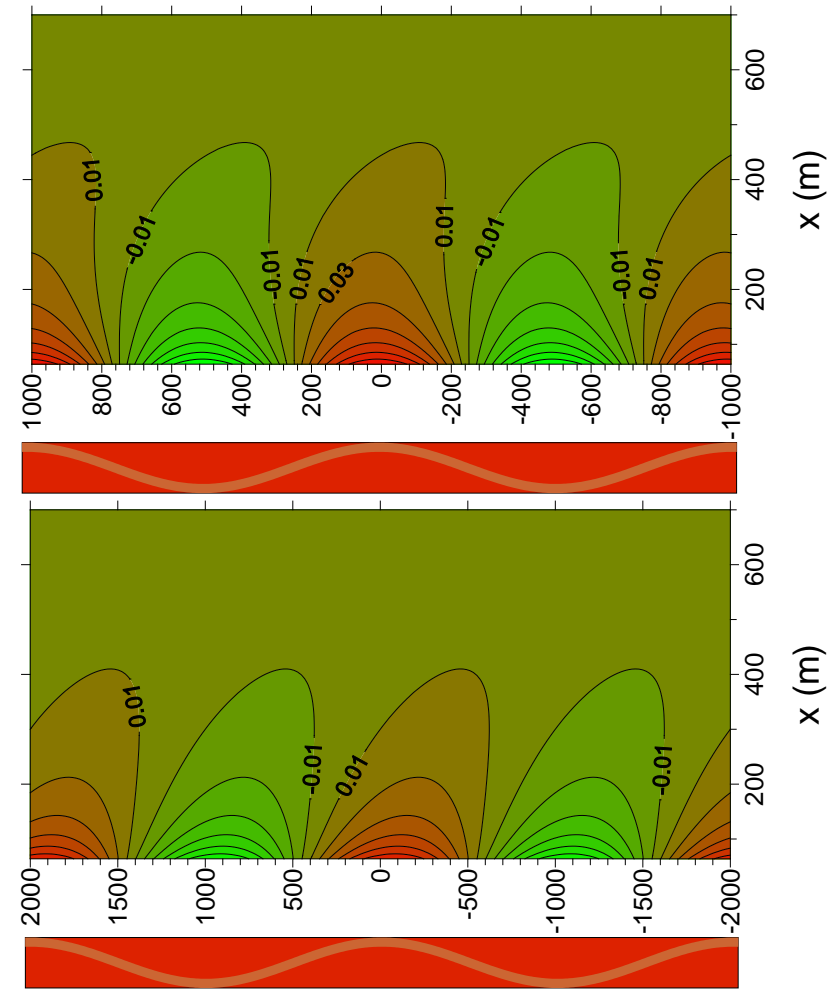

Figure 6. Perturbation in the wave height field, $H^{\prime}(x, y)$, from deep water up to breaking, for $L=1 \mathrm{~km}$ (upper panel) and for $L=2 \mathrm{~km}$ (lower panel). Model parameters are indicated in the text. The sand wave shape is indicated by a brown line (crest at $y=0$ ). The wave direction is from the right. The unperturbed shoreline is at $x=0$ and the unperturbed breaker line is at $x=64 \mathrm{~m}$.

The explanation is that the position of the maximum in wave energy appears to be governed by the competition between two opposite effects. On the one hand, the refractive wave crests stretching causes a wave energy dispersion that is more intense when the wave rays are more bended. This effect is maximum at I2 (where waves experience a stronger refraction) and minimum at I1. Thus, this process brings the maximum in $\mathrm{H}(\mathrm{x}, \mathrm{y})$ near I1 and is the main physical process responsible for HAWI (Falqués 2011b, van den Berg 2012a). On the other hand, wave refraction also focuses wave energy near the crests bringing the maximum in $\mathrm{H}(\mathrm{x}, \mathrm{y})$ near $\mathrm{C}$ (exactly at $\mathrm{C}$ for normal wave incidence and somewhat downdrift for oblique wave incidence). The wave focusing effect is dominant only for very short sand waves while wave energy dispersion effect is dominant for intermediate to long sand waves. 


\section{Existence of a dominant wavelength}

The analysis of the location of the maximum $Q$ shows that in the neighborhood of $L_{c}$ the growthrate $\sigma_{\mathrm{r}}(\mathrm{L})$ shifts from negative to positive values so that it is an increasing function of $\mathrm{L}$. However, there is an opposing effect that reverses this tendency and causes $\sigma_{\mathrm{r}}(\mathrm{L}) \rightarrow 0$ for $\mathrm{L} \rightarrow \infty$. As $\mathrm{L}$ increases, the difference between maximum and minimum shoreline angle with respect to the mean, $\Delta$ $\phi$, for a given amplitude A, decreases . This has two consequences. First, the difference in relative wave angle, $\Delta \alpha_{b}$, decreases. On the other hand, $\Delta \mathrm{H}_{\mathrm{b}}$ caused by wave energy, dispersion decreases too. Then, according to Eq. 2, the maximum alongshore variation of $\mathrm{Q}, \Delta \mathrm{Q}$, decreases with increasing $\mathrm{L}$. Second, since the morphological evolution is driven by the gradients in $\mathrm{Q}$, which are proportional to $\Delta \mathrm{Q} / \mathrm{L}$, the growth rate decreases to 0 for large $\mathrm{L}$. As a result, there exists a maximum gowthrate for $\mathrm{L}=\mathrm{L}_{\mathrm{M}}$.

\section{PARAMETRIC TRENDS OF THE WAVELENGTH}

In order to find on which factors sand wave wavelength essentially depends we will avoid introducing lengthscales that are not essential to HAWI development and that could mask the fundamental dependence. To this end, a planar beach of slope $\beta$

$$
D_{0}(x)=\beta x
$$

provides the simplest beach profile. Regarding the perturbed bathymetry, the simplest option is to assume that if the shoreline shifts offshore or onshore, the whole profile shifts accordingly keeping its shape up to the depth of closure, $\mathrm{D}_{\mathrm{c}}$. This means that the shape function in Eq. 9 is of the form

$$
f(x)=\left\{\begin{array}{lll}
1 & \text { if } & x<x_{c} \\
0 & \text { if } & x \geq x_{c}
\end{array}\right.
$$

Notice that the perturbed profile has a small jump at $x=x_{c}$ but as long as $D_{c}$ is taken quite large in comparison with $\lambda_{0}$ its effect on wave transformation is not significant.

The sensitivity analysis is done in terms of the wave height, angle and period in deep water $\left(\mathrm{H}_{0}, \theta_{0}\right.$, $\mathrm{T})$, the beach slope, $\beta$, and the breaking index, $\gamma_{\mathrm{b}}$.

Consistently with Falqués and Calvete (2005), for $\theta_{0}$ and $D_{c}$ large enough, and $T$ small enough, growthrates are positive for certain range of sand wave wavelengths, L. In such a case, as shown in Fig. 2 , the instability curve, $\sigma_{\mathrm{r}}-\mathrm{L}$, typically rises from negative growthrates, reaches a positive maximum $\sigma_{\mathrm{M}}$ for $\mathrm{L}=\mathrm{L}_{\mathrm{M}}$ and then decays very smoothly and asymptotically to zero without crossing the $\sigma_{\mathrm{r}}=0$ axis.

An important parameter is the depth of closure, $D_{c}$, whose order of magnitude in nature is $O(10 \mathrm{~m})$. However, we have found that using values in the realistic range introduces a length scale that interferes with $\lambda_{0}$ to determine the sand wave length, $L_{M}$. This is because long water waves $\left(\lambda_{0} / 2>D_{c}\right)$ start to feel the sea bed where it is still unperturbed whereas short water waves $\left(\lambda_{0} / 2<D_{c}\right)$ only feel the perturbed bathymetry. To avoid this effect we used an unrealistically large depth of closure, $\mathrm{D}_{\mathrm{c}}=100 \mathrm{~m}$, as default value in the present section. The effect of smaller values is discussed later on (see also, van den Berg et al. (2012b)).

The first result of the model computations is that the sand wave wavelength, $L_{M}$, is inversely proportional to the beach slope, $\beta$. This becomes clear from Fig. 7 , which shows $L_{M}$ as a function of $\beta^{-1}$ for several wave conditions. The solid lines are linear fits and it can be seen that they are strikingly good, with $\mathrm{R}^{2}>0.999$. Thus, changing the beach slope and keeping the other parameters fixed only changes the horizontal scaling of the processes but not the processes themselves (van den Berg et al. $2012 b$ ). In the remaining of this section the default value $\beta=0.03$ will be used unless stated otherwise.

The second result is that for each slope $\beta$, wave angle $\theta_{0}$ and wave height $H_{0}, L_{M}$ is roughly proportional to the water wave length, $\lambda_{0}$. This can be seen in Fig. 8a, where $L_{M}$ is plotted against $\lambda_{0}$ for several wave angles. The relationship is nearly linear for moderate angles and deviates somewhat from linearity for large $\lambda_{0}$ in case of large angles, specially for $\theta_{0}=80^{\circ}$. Thus, keeping $\beta=0.03$, the ratio $L_{M}$ $/ \lambda_{0}$ is roughly constant. But given the proportionality between $L_{M}$ and $\beta$, this can be extended to state that the ratio $\beta \mathrm{L}_{\mathrm{M}} / \lambda_{0}$ is relatively constant for each wave angle. This quantity is plotted in Fig. 8b against wave period, $\mathrm{T}$, and it is seen that the ratio is in the range 2-2.5 for moderate angles and rises up to about 5 for large angles.

The relation between $L_{M}$ and $\lambda_{0}$ also depends on $D_{c}$. If smaller values than $D_{c}=100 \mathrm{~m}$ are considered, the relationship deviates gradually from linearity by increasing the wave period and this is more pronounced for large angles. Fig. 9 shows that relationship for $D_{c}=30 \mathrm{~m}$ and it is seen that 
linearity only holds up to $\lambda_{0} \approx 60 \mathrm{~m}$, i.e., up to $\lambda_{0} / 2 \approx \mathrm{D}_{\mathrm{c}}$. This is because shorter waves feel only the perturbed depth contours whereas longer waves feel both the perturbed and the unperturbed bathymetry.

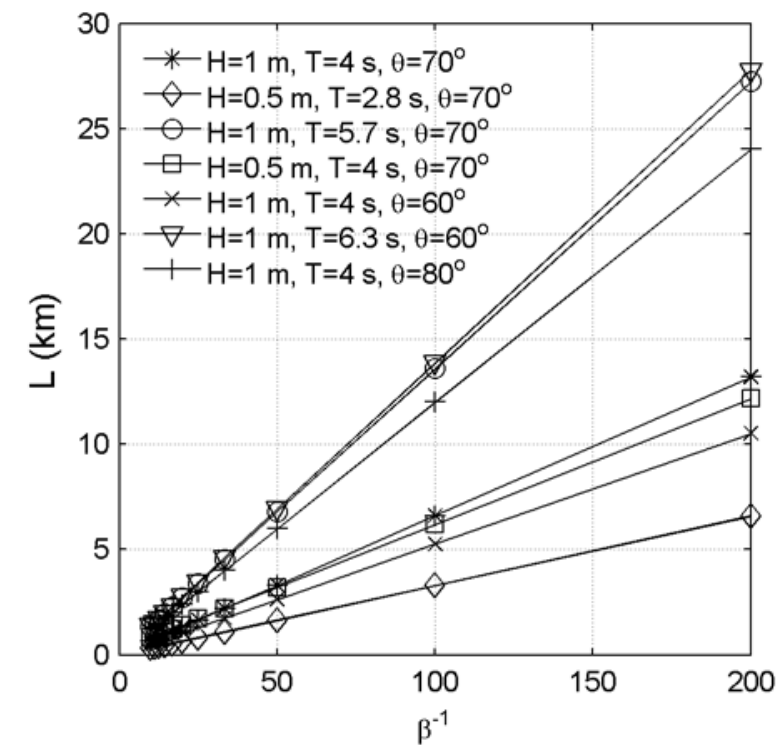

Figure 7. Sand wave wavelength, L, as a function of the inverse of the beach slope $\beta^{-1}$. Symbols represent the model computations and the solid lines are the corresponding linear fits.

a

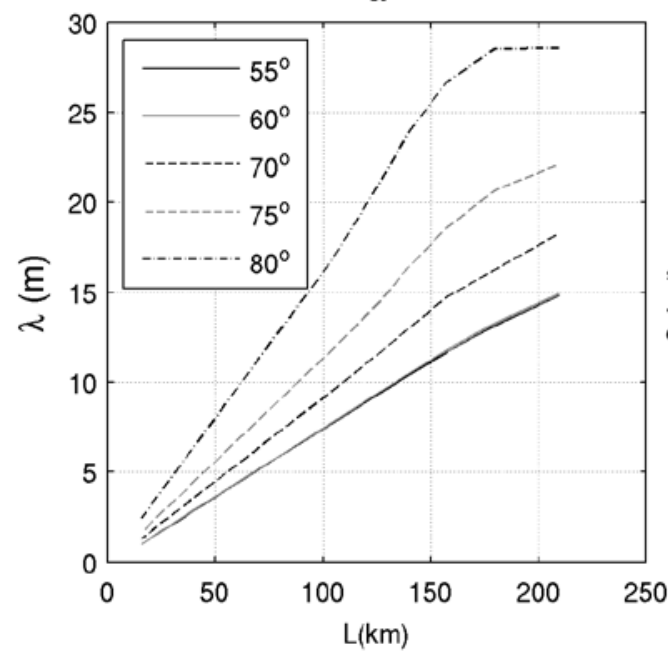

b

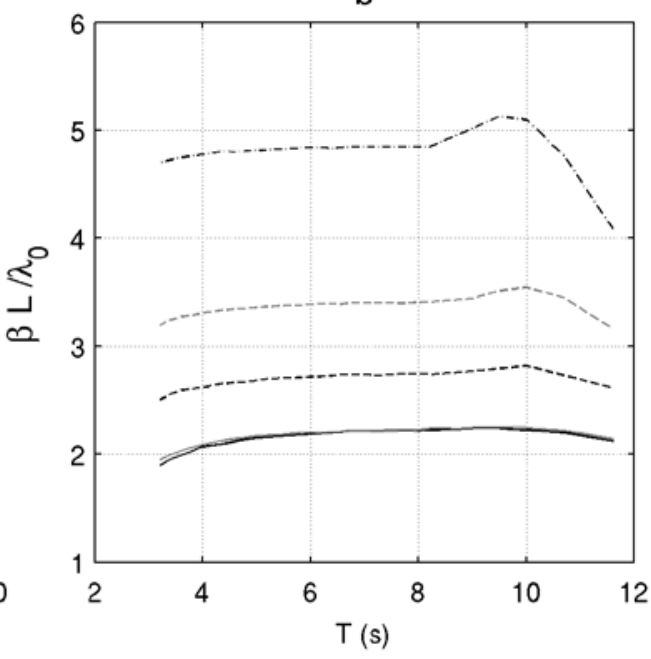

Figure 8. (a): Sand wave wavelength, $L$, as a function of the water wave wavelength in deep water, $\lambda_{0}$, for the default values of the other parameters and for $\theta_{0}=50,55,60,65,70,75,80^{\circ}$. (b): $\beta L / \lambda_{0}$ parameter corresponding to the curves in a), as a function of wave period, $\mathrm{T}$.

Finally, there is little influence of the breaking index, $\gamma_{b}$ on the sand wave wavelength. This was found by comparing $\gamma_{b}=0.4,0.6$ and 0.8. Similarly, wave height has no influence on $L_{M}$ for this idealized geometry.

\section{DISCUSSION AND CONCLUSIONS}

The essence of growth/decay and migration of sandwaves can be captured by looking at the gradients in the total alongshore transport rate $\mathrm{Q}$. On an undulating shoreline a maximum Q updrift (downdrift) of a crest will cause sediment transport convergence (divergence) at the crest so that the sand wave will grow (decay). Looking at the alongshore distribution of Q for small amplitude sand 
waves with several wavelengths, L, it is found that shoreline instability and wavelength selection is governed by the interplay of three processes. The first one is the direct effect of relative wave angle

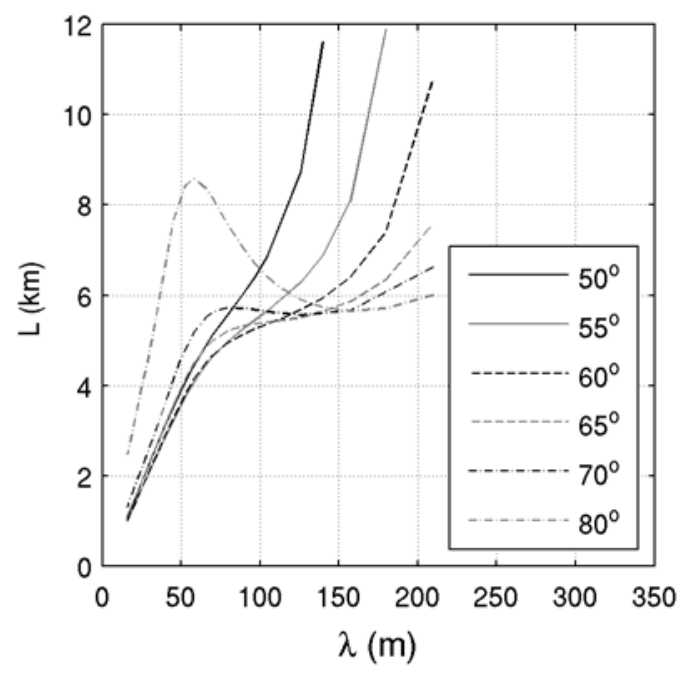

Figure 9. Sand wave wavelength, L, as a function of the water wave wavelength in deep water, $\lambda_{0}$, for $\theta_{0}=50$, $55,60,65,70,75,80^{\circ}$ and for $D_{c}=30 \mathrm{~m}$. The default values are considered for the other parameters.

(A): this angle is maximum downdrift of the crest causing there a maximum Q. This effect is always stabilizing. The second one is the refractive wave energy spreading which is less at the updrift flank of the crest than at the downdrift side (B). It produces maximum energy, hence maximum Q, at the updrift side so that it is always a de-stabilizing effect. If the wave angle at the depth of closure is roughly above $45^{\circ}$ (B) dominates and the shoreline is unstable. The third effect depends on the curvature (C): wave focusing (de-focusing) by the capes (bays). It causes maximum energy (and maximum transport) slightly downdrift of the crest. Therefore, it weakens the instability. It is found that (B) is generally dominant except for short sand waves, for which $(\mathrm{C})$ takes over. This is why there is a minimum wavelength $L_{c}$ for sand wave formation. For large $L\left(>L_{c}\right)$ the growthrate decreases because even though the position of the maximum $\mathrm{Q}$ favours instability, the magnitude of the gradients in $\mathrm{Q}$ decreases. This is why there is an optimum wavelength, $\mathrm{L}_{\mathrm{M}}>\mathrm{L}_{\mathrm{c}}$.

The dominant wavelength, $\mathrm{L}_{\mathrm{M}}$, scales with the water wavelength, $\lambda_{0}$ and is inversely proportional to the beach slope, $\beta$. The proportionality factor depends on the wave angle and ranges between 2 and 5 . This was founs for a very idealized geometry and for a very large $\mathrm{D}_{\mathrm{c}}$. Whether this can be applicable to more realistic geometries is discussed in van den Berg et al. (2012b).

This study is conceptual and it was just meant to unravel the physical explanation for the existence of a wavelength selection and to find out the main parametric trends of the dominant wavelength. Therefore, we have used a simple approach: one-line shoreline modeling and geometric optics approximation for wave refraction and shoaling. A step forward could be to consider spectral waves, for instance by using SWAN model to investigate the alongshore position of the maximum $Q$ for a slightly undulating coastline. This would allow to investigating how robust the present results are and if they depend on the shape of the spectrum or on the directional spreading.

On the other hand, the limitations of the one-line modeling do not seem to be essential since the present results are qualitatively similar to those obtained by using a nonlinear quasi-2D model (not shown, but a preliminary exploration can be seen in van den Berg (2012c)). Also, the study of List and Ashton (2007) shows that computing Q with the CERC formula (as we have done) or from a fully 2D process-based model (Delft3D) give qualitatively similar results.

\section{ACKNOWLEDGMENTS}

This research has been funded by the Spanish Ministerio de Ciencia e Innovación, through the research project 'Modelización y monitorización integradas en morfodinámica de playas naturales y regeneradas’ (CTM2009-11892/IMNOBE). The second author is supported by a FPI scholarship of the Spanish government within the research Project CTM2006-08875/MAR 


\section{REFERENCES}

Alves A. R. 2009. Long term erosional hot spots in the southern Brazilian coast. Journal of Geophysical Research, 114, C02020, doi:10.1029/2008JC004933.

Ashton, A., A. B. Murray and O. Arnault 2001. Formation of coastline features by large-scale instabilities induced by high-angle waves. Nature, 414, 296-300.

Ashton, A., and A. B. Murray 2006a. High-angle wave instability and emergent shoreline shapes: 1. Modeling of sand waves, flying spits, and capes. Journal of Geophysical Research, 111, F04011,doi:10.1029/2005JF000422.

Ashton, A., and A. B. Murray 2006b. High-angle wave instability and emergent shoreline shapes: 2. Wave climate analysis and comparisons to nature. Journal of Geophysical Research, 111, F04012, doi:10.1029/2005JF000423.

Bruun, P. 1954. Migrating sand waves or sand humps, with special reference to investigations carried out on the Danish North Sea Coast, Proceedings of $5^{\text {th }}$ International Conference on Coastal Engineering, ASCE, 269-295.

Caballeria, M., A. Falqués, N. van den Berg 2011. Potential instabilities of Catalan coastline induced by high-angle waves. Proceedings of the $7^{\text {th }}$ IAHR Symposium on River, Coastal and Estuarine Morphodynamics, cd-rom

Davidson-Arnott, R. G. D. and A. van Heyningen 2003. Migration and sedimentology of longshore sandwaves, Long Point, Lake Erie, Canada. Sedimentology, 50, 1123-1137.

Falqués, A., and D. Calvete 2005. Large scale dynamics of sandy coastlines. Diffusivity and instability. Journal of Geophysical Research, 110, C03007, doi:10.1029/2004JC002587.

Falqués, A., N. van den Berg, F. Ribas and M. Caballeria 2011a. Modelling shoreline sand waves. Application to the coast of Namibia. Proceedings of the $7^{\text {th }}$ IAHR Symposium on River, Coastal and Estuarine Morphodynamics, cd-rom.

Falqués, A., D. Calvete and F. Ribas 2011b. Shoreline Instability due to Very Oblique Wave Incidence: Some Remarks on the Physics. Journal of Coastal Research, 27(2), 291-295.

Gravens, M. B. 1999. Periodic shoreline morphology, Fire Island, New York. Proceedings of Coastal Sediments'99, ASCE, 1613-1626.

Guillén J., M. J. F. Stive and M. Capobianco 1999. Shoreline evolution of the Holland Coast on a decadal scale. Earth Surface Processes and Landforms, 24, 517-536.

Inman, D. L., M. H. S. Elwany, A. A. Khafagy and A. Golik 1992. Nile Delta Profiles and Migrating Sand Blankets. Proceedings of $23^{\text {th }}$ International Conference on Coastal Engineering, ASCE, 269295.

Kaergaard, K., J. Fredsoe and S. B. Knudsen 2011. Coastline undulations on the West Coast of Denmark: Offshore extent, relation to breaker bars and transported sediment volume. Coastal Engineering, 60, 109-122.

Komar, P. D. 1998. Beach Processes and Sedimentation, Prentice-Hall, Englewood Cliffs, New Jersey, 544.

List, J. H. and A. D. Ashton 2007. A circulation modeling approach for evaluating the conditions for shoreline instabilities. Proceedings of Coastal Sediments 2007, ASCE, 327-340.

Medellín, G., R. Medina, A. Falqués and M. González 2008. Coastline sand waves on a low energy beach at 'El Puntal' spit, Spain. Marine Geology, 250, 143-156.

Medellín, G., A. Falqués, R. Medina and M. González 2009. Sand waves on a Low-Energy Beach at 'El Puntal' Spit, Spain: Linear Stability Analysis. Journal of Geophysical Research, 114, C03022, doi:10.1029/2007JC004426.

Pelnard-Considère, R. 1956. Essai de theorie de l'Evolution des Formes de Rivage en Plages de Sable et de Galets. Proceedings of the 4th Journees de l'Hydraulique, LesEnergies de la Mer, Paris, Société Hydrotechnique de France, III(1), 289-298.

Ruessink, B. G. and M. C. J. L. Jeuken 2002. Dunefoot dynamics along the Dutch coast. Earth Surface Processes and Landforms, 27, 1043-1056.

Ryabchuk, D., I. Leontyev, A. Sergeev, E. Nesterova, L. Sukhacheva and V. Zhamoida 2011. The morphology of sand spits and the genesis of longshore sand waves on the coast of the eastern Gulf of Finland. Baltica 24 (1), 13-24.

Stive, M. J. F., S. G. J. Aarninkhof, L. Hamm, H. Hanson, M. Larson, K. M. Wijnberg, R. J. Nicholls and M. Capobianco 2002. Variability of shore and shoreline evolution. Coastal Engineering, 47, 211-235.

Thevenot M. M. and N. C. Kraus 1995. Longshore sandwaves at Southampton Beach, New York: 
observations and numerical simulation of their movement. Marine Geology, 126, 249-269.

Uguccioni, L., R. Deigaard and J. Fredsoe 2006. Instability of a coastline with very oblique wave incidence. Proceedings of $30^{\text {th }}$ International Conference on Coastal Engineering, ASCE, 35423553.

Van den Berg, N., A. Falqués, F. Ribas. 2012a. Modeling large scale shoreline sand waves under oblique wave incidence. Journal of Geophysical Research, 117, F03019, doi:10.1029/2011JF002177.

Van den Berg, N., A. Falqués, F. Ribas, M. Caballeria. 2012b. On the wavelength of self-organized shoreline sand waves. Journal paper to be submitted.

Van den Berg 2012c. Modelling the dynamics of large scale shoreline sand waves, $\mathrm{PhD}$ thesis, Universitat Politècnica de Catalunya, Barcelona, 130 pp.

Verhagen, H. J. 1989. Sand waves along the Dutch Coast. Coastal Engineering, 13, 129-147.

Vila-Concejo A., A. D. Short, M. G. Hugues and R. Ranasinghe 2009. Formation and evolution of a sandwave on an estuarine beach. Journal of Coastal Research, 56, 153-157. 